\title{
Exploring the Gender Gap in Science, Technology, Engineering, and Mathematics (STEM), and Soft Skills, and Knowledge of Role of Models Among Students in Rural Uganda
}

\author{
Angella Musiimenta ${ }^{1}$, Wilson Tumuhimbise ${ }^{1}$, Elly Bangumya ${ }^{1}$, Aaron T Mugaba ${ }^{1}$, Robert Mugonza ${ }^{1}$, Phionah \\ Kobutungi ${ }^{1}$ \& Michael J Nankunda ${ }^{1}$ \\ ${ }^{1}$ Information Technology Department, Mbarara University of Science and Technology, Mbarara, Uganda \\ Correspondence: Angella Musiimenta, PhD, Department of Information Technology, Mbarara University of \\ Science and Technology, P.O. Box 653, Mbarara, Uganda. Tel: 256-776-820-598. E-mail: \\ amusiimenta@must.ac.ug
}

Received: August 21, 2019

Accepted: September 17, 2019

Online Published: December 14, 2019

doi:10.20849/jed.v3i3.621

URL: https://doi.org/10.20849/jed.v3i3.621

\begin{abstract}
Background: Globally, women's representation in STEM fields remains significantly lower than that of men. Studies assessing the STEM gender gap in disadvantaged rural-based schools are lacking.

Objective: To examine the gender differences in attitudes towards STEM and soft skills, and knowledge of role models among students of Nakivale secondary school in Nakivale refugee settlement, southwestern Uganda.
\end{abstract}

Methods: We employed a cross sectional study design that administered pilot tested questionnaires to 111 secondary school students in Nakivale secondary school.

Results: More girls than boys reported negative attitudes towards STEM. Both boys and girls demonstrated low attitudes towards the $21^{\text {st }}$ century skills (such as goal setting, leadership skills, team work skills, time management and computer/internet skills), low intentions of pursuing STEM-related subjects in future, as well as limited exposure to STEM role models.

Implication: Interventions to address girls' negative attitudes towards STEM, improve students' $21^{\text {st }}$ century skills, develop students' interest in STEM subjects/careers, and link students to role models are urgently needed especially in marginalized areas such as refugee settlements.

Keywords: STEM, soft skills, role models, attitudes, girls in STEM, gender gap, students, refugee settlement

\section{Introduction}

World over the representation of women and girls in STEM fields is significantly lower than men (Watt, 2010). Causes of gender imbalance in STEM subjects include girls' negative perceptions and lower self-esteem, lack of role models, and discouragement from teachers and parents (Dickerson, McIntosh, \& Valente, 2015). STEM improves human mind, intellectualism, critical thinking and rational thoughtfulness development (Genlott \& Grönlund, 2016). A nation's investment in science and technology education and innovation has transformational impact on its economy and addressing the unemployment crisis (Nuwagaba, 2012). In the past decade, a majority of African nations have identified their need for development in science and technology and are strategically identifying ways to enhance their capacity in the STEM fields as a way to achieve industrial development and social transformation. Despite these efforts, little is known about STEM education and training in Africa outside of a number of comparative studies focused on South Africa (Marginson et al, 2013). The dearth of general studies on STEM in Africa contributes to a further gap in our understanding of the gender gap in STEM. The Ugandan government is strongly emphasizing STEM development by investing more resources in improving access to STEM career (UNESCO, 2010). Uganda's National Planning Authority launched the Uganda Vision 2040 in 2013. This development plan emphasizes gender equality and stresses the importance of mainstreaming gender in STEM fields. Despite these efforts, women and girls continue to be underrepresented in key STEM subjects such as computer science (Ochwa-Echel, 2011). In attempt to encourage girl's participant in STEM subjects, Uganda made all science subjects compulsory at ordinary level of education in 2004. These efforts could have been more impactful if combined with a thorough understand of the factors that constrain girls' 
involvement in STEM, as well putting strategies to address these barriers.

There are increasing number of studies that demonstrate the importance of STEM graduates to have soft skills in addition to technical skills (Rosenberg et al, 2012; Willmot \& Colman, 2016). Davidson, (2017) in her book 'The new education' states that graduates need to be equipped with skills to succeed in a complex world. She emphasizes the need for "so-called soft skills, including strategies, methods and tactics for successful communication and collaboration." These skills are necessary in order to ensure career success and adaptability in the changing world of work.

Google studies on workplace success found that contrary to STEM's traditional focus on hard skills, the seven primary attributes of success at Google are all soft skills with technical skills coming in eighth (Davidson, 2017). Further studies on productive teams also highlighted the importance of soft skills in high tech environments (Strauss, 2017). Therefore, equipping students with soft skills could have significant impact on their chances of finding employment and career success in the long term.

Overall, despite the potential benefits of STEM and soft skills, studies documenting the gender gap in STEM and soft skills in rural Uganda are lacking. Such studies would be useful in formulating evidence-based practices that would help Uganda achieve its objective of mainstreaming gender in STEM education as part of its national development plan. While implementing our on-going electronic learning project in schools within Nakivale refugee settlement, of which Nakivale Secondary school is beneficiary, we realized that over $70 \%$ of students especially girls do not perform well in science-related subjects such as mathematics, biology, chemistry and physics. Against this background, this study aims to examine the gender differences in attitudes towards STEM and soft skills among students of Nakivale secondary school, found in Nakivale refugee settlement.

\section{Method}

\subsection{Study Design and Setting}

This study involved administering pilot tested questionnaires in a quantitative cross sectional study design. Students from senior four class of Nakivale Secondary school were recruited to assess their attitudes towards STEM courses and their soft skills from. Nakivale Secondary School is the only secondary school within Nakivale Refugee settlement, which is the $8^{\text {th }}$ biggest refuge settlement in the world with a population of over 115000 people located in Isingiro district, in rural south western Uganda. The settlement currently hosts refugees from various parts of the world including: Rwanda, Congo, Burundi, Somalia, Eritrea, Sudan, and Kenya. Commenced in 2010 Nakivale Secondary School has a student population of 1114, of which 447 are girls while 667 are boys. Of the total student population, 895 students (326 girls, 569 boys) are refugees, while 219 (121 girls, 98 boys) are Ugandan nationals. The school offers both ordinary level (senior 1-4) and advanced (senior 5-6) levels of education. At ordinary level, the failure rate of science-related subjects such as mathematics, biology, chemistry and physics is over $70 \%$. Per the education system of Uganda, science subjects are compulsory in ordinary level. However, at an advanced level, taking sciences is optional. At advanced level, the only STEM subjects offered are mathematics (currently pursued by 2 girls and 13 boys) and physics (currently pursued by 1 girl and 6 boys).

\subsection{Sampling and Study Participants}

This study employed quantitative approach that involved administering questionnaires to all senior four students at Nakivale Secondary School who were present on the day of data collection, and consented to participate in the study. Senior four being the last class in the ordinary level, we saw it interesting to examine students' attitudes before they could make important choices about the subject combinations to be taken at an advanced level.

\subsection{Data Collection}

We administered the questionnaires in March 2019 to 111 senior four students from Nakivale Secondary School. We adopted a pretested questionnaire designed and pilot tested by (Faber et al., 2013) for assessing the students' attitudes towards STEM (Mathematics, Science, Engineering and Technology) and soft skills. The survey enabled the collection of information on socio-demographics, attitudes towards STEM, $21^{\text {st }}$ Century Skills, the students' opinions about their future courses and their expectation about their performance.

\subsection{Data Analysis}

We used SPSS 20 to generate descriptive statistics about students' sociodemographic information, and attitudes about STEM, $21^{\text {st }}$ Century Skills, opinions about their future courses, and expectation about their performance.

\subsection{Ethical Reviews}

All participants provided signed informed consent before study participation. Ethical approval was obtained 
from the Institutional Review Committee of Mbarara University of Science and Technology, and the Uganda National Council for Science and Technology.

\section{Results}

\subsection{Participants' Characteristics}

This study involved a total of 111 senior four students from Nakivale Secondary School. As shown in the table 1 below, the majority of students were of Democratic Republic of Congo Nationality $(n=36,32.4 \%)$. The majority $(n=70,63.1 \%)$ were in the age category of $14-19$. Females were $52(46.8 \%)$. The majority of students had both parents $(70,63.1 \%)$, who majorly depended on subsistence farming $(72,66.1 \%)$.

Table 1. Social demographic details of the participants

\begin{tabular}{ll}
\hline Characteristic & $\mathbf{N}=\mathbf{1 1 1}$ \\
\hline Age & $70(63.1 \%)$ \\
\hline $14-19$ & $41(36.9 \%)$ \\
\hline $20-24$ & \\
\hline Gender & $59(53.2 \%)$ \\
\hline Male & $52(46.8 \%)$ \\
\hline Female & \\
\hline Nationality & $33(29.7 \%)$ \\
\hline Uganda & $1(0.9 \%)$ \\
\hline Somalia & $16(14.4 \%)$ \\
\hline Rwanda & $19(17.1 \%)$ \\
\hline Burundi & $36(32.4 \%)$ \\
\hline Congo & $3(2.7 \%)$ \\
\hline Ethiopia & $2(1.8 \%)$ \\
\hline South Sudan & $1(0.9 \%)$ \\
\hline Tanzania & \\
\hline Parental Status & $70(63.1 \%)$ \\
\hline Have both parents & $34(30.6 \%)$ \\
\hline Have one parent & $7(6.3 \%)$ \\
\hline Have none of the parents & \\
\hline Occupation of the Parents & $72(66.1 \%)$ \\
\hline Peasant/ Subsistence farmer & $7(6.4 \%)$ \\
\hline Formal Employment & $30(27.5 \%)$ \\
\hline Small Business owner & \\
\hline
\end{tabular}

\subsection{Main Findings}

Table 2. Students attitudes towards mathematics

\begin{tabular}{|c|c|c|c|c|}
\hline \multirow[t]{2}{*}{ Statement } & Boys & Girls & Boys & Girls \\
\hline & \multicolumn{2}{|c|}{ Agree } & \multicolumn{2}{|c|}{ Disagree } \\
\hline I can get good grades in maths. & $30(50.8 \%)$ & $9(17.3 \%)$ & $29(49.1 \%)$ & $43(82.7 \%)$ \\
\hline Maths is hard for me & $26(44.1 \%)$ & $32(61.5 \%)$ & $33(55.9 \%)$ & $20(38.5 \%)$ \\
\hline $\begin{array}{l}\text { I can handle most subjects well, but cannot do a } \\
\text { good job with maths }\end{array}$ & $26(44.1 \%)$ & $30(57.7 \%)$ & $33(55.9 \%)$ & $22(42.3 \%)$ \\
\hline I would consider a career that uses maths & $27(45.8 \%)$ & $10(19.2 \%)$ & $32(54.2 \%)$ & $42(80.8 \%)$ \\
\hline
\end{tabular}


Table 2 above indicates that more boys than girls agreed that they can get good grades in mathematics. More girls $(n=32,61.5 \%)$ than boys $(n=26,44.1 \%)$ agreed that mathematics is hard. The minority of boys $(n=27$, $45.8 \%)$ and girls $(n=10,19.2 \%)$ agreed that they would consider a career that uses mathematics.

Table 3. Students attitudes towards science

\begin{tabular}{lllll}
\hline \multirow{2}{*}{ Statement } & Boys & Girls & Boys & Girls \\
\cline { 2 - 5 } & \multicolumn{2}{c}{ Agree } & \multicolumn{2}{c}{ Disagree } \\
\hline I can do well in science & $29(49.2 \%)$ & $17(32.7 \%)$ & $30(50.8 \%)$ & $35(67.3 \%)$ \\
\hline I am considering a career in science & $30(50.8 \%)$ & $16(30.8 \%)$ & $29(49.2 \%)$ & $36(69.2 \%)$ \\
\hline Science will be important in my future work & $35(59.3 \%)$ & $18(34.6 \%)$ & $24(40.7 \%)$ & $34(65.4 \%)$ \\
\hline I can do a good job with science & $37(62.7 \%)$ & $19(36.5 \%)$ & $22(37.3)$ & $33(63.5 \%)$ \\
\hline
\end{tabular}

Table 3 above indicates that compared to girls $(n=17,32.7 \%)$, boys are more likely to believe that they can do well in sciences $(n=29,49.2 \%)$. More boys $(n=30,50.8 \%)$ than girls $(n=16,30.8 \%)$ were more likely to consider a career in science. More boys $(n=37,62.7 \%)$ than girls $(n=19,36.5 \%)$ agreed that they can do a good job with science.

Table 4. Students attitudes towards engineering and technology

\begin{tabular}{lllll}
\hline \multirow{2}{*}{ Statement } & Boys & Girls & Boys & Girls \\
\cline { 2 - 5 } & \multicolumn{2}{c}{ Agree } & \multicolumn{2}{c}{ Disagree } \\
\hline I like to imagine creating new products & $30(50.8 \%)$ & $20(38.5 \%)$ & $29(49.1 \%)$ & $33(63.5 \%)$ \\
\hline I am interested in what makes machines work & $32(54.2 \%)$ & $17(32.7 \%)$ & $27(45.8 \%)$ & $35(67.3 \%)$ \\
\hline I am good at building and fixing things. & $39(66.1 \%)$ & $18(34.6 \%)$ & $20(33.9 \%)$ & $34(65.4 \%)$ \\
\hline I am considering a career & in $28(47.5 \%)$ & $20(38.5 \%)$ & $31(52.5)$ & $33(63.5 \%)$ \\
engineering/technology & & & & \\
\hline
\end{tabular}

Table 4 above indicates that more boys $(n=30,50.8 \%)$ than girls $(n=20,38.5 \%)$ agreed that they like to imagine creating new products. More boys $(n=32,54.2 \%)$ than girls $(n=17,32.7 \%)$ reported being interested in what makes machines work. More boys $(n=39,66.1 \%)$ than girls $(n=18,34.6 \%)$ are good at building and fixing things. Less than average number of boys $(n=28,47.5 \%)$ and girls $(n=20,38.5 \%)$ agreed that they are considering a career in engineering/technology.

Table 5. Students' future interests STEM

\begin{tabular}{lcccc}
\hline \multirow{2}{*}{\multicolumn{1}{c}{ Statement }} & Boys & Girls & Boys & Girls \\
\cline { 2 - 5 } & & Interested & \multicolumn{2}{c}{ Not interested } \\
\hline Interested in biology & $29(49.1 \%)$ & $20(38.5 \%)$ & $30(50.8 \%)$ & $32(61.5 \%)$ \\
\hline Interested in physics & $22(37.3 \%)$ & $17(32.7 \%)$ & $37(62.7 \%)$ & $35(67.3 \%)$ \\
\hline Interested in chemistry & $19(32.2 \%)$ & $14(26.9 \%)$ & $40(67.8 \%)$ & $38(73.1 \%)$ \\
\hline Interested in mathematics & $30(50.8 \%)$ & $19(36.5 \%)$ & $29(49.2 \%)$ & $33(63.5 \%)$ \\
\hline Interested in technology & $29(49.2 \%)$ & $18(34.6 \%)$ & $30(50.8 \%)$ & $34(65.4 \%)$ \\
\hline Interested in engineering & $26(44.1 \%)$ & $15(28.8 \%)$ & $33(55.9 \%)$ & $37(71.2 \%)$ \\
\hline
\end{tabular}

According to Table 5 above, students generally showed less future interest in specific scientific subjects (such as biology, physics, and chemistry), mathematics, technology and engineering. The majority of students were disinterested in chemistry-boys $(n=40,67.8 \%)$, girls $(n=38,73.1 \%)$. 
Table 6. Knowledge STEM professionals

\begin{tabular}{lllll}
\hline \multicolumn{1}{c}{ Statement } & \multicolumn{3}{c}{ Gender } & Total (111) \\
\cline { 2 - 4 } & & Boys (59) & Girls (52) & \\
\hline I know adults who work as scientists & Yes & $31(52.5 \%)$ & $30(57.7 \%)$ & $61(54.9 \%)$ \\
\cline { 2 - 5 } & No & $28(47.5 \%)$ & $17(32.7 \%)$ & $40(36.1 \%)$ \\
\hline I know adults who work as engineers & Yes & $34(57.6 \%)$ & $33(63.5 \%)$ & $67(60.4 \%)$ \\
\cline { 2 - 5 } & No & $25(42.4 \%)$ & $19(36.5 \%)$ & $44(39.6 \%)$ \\
\hline I know adults who work as mathematicians & Yes & $35(59.3 \%)$ & $32(61.5 \%)$ & $67(60.4 \%)$ \\
\cline { 2 - 5 } & No & $24(40.7 \%)$ & $20(38.5 \%)$ & $44(39.6 \%)$ \\
\hline I know adults who work as technologists & Yes & $30(50.8 \%)$ & $31(59.6 \%)$ & $61(55.0 \%)$ \\
\cline { 2 - 5 } & No & $29(49.1 \%)$ & $21(40.4 \%)$ & $60(54.1 \%)$ \\
\hline
\end{tabular}

Table 6 above indicates that both boys and girls have had relative knowledge about adults who work as scientists, engineers, mathematicians, and technologists.

Table 7. Students' attitude towards $21^{\text {st }}$ Century skills

\begin{tabular}{llccc}
\hline \multirow{2}{*}{ Statement } & Boys & Girls & Boys & Girls \\
\cline { 2 - 5 } & \multicolumn{2}{c}{ Agree } & \multicolumn{2}{c}{ Disagree } \\
\hline I can set my own learning goals & $28(47.5 \%)$ & $22(42.3 \%)$ & $31(52.5 \%)$ & $30(57.7 \%)$ \\
\hline I can lead others to accomplish a goal & $27(45.8 \%)$ & $16(30.8 \%)$ & $32(54.2 \%)$ & $36(69.2 \%)$ \\
\hline I can work with others to accomplish a goal & $26(44.1 \%)$ & $28(53.8 \%)$ & $33(56.3 \%)$ & $24(46.1 \%)$ \\
\hline $\begin{array}{l}\text { I can manage time wisely when working on } \\
\text { alone }\end{array}$ & $25(42.4 \%)$ & $23(44.2 \%)$ & $34(57.6 \%)$ & $29(55.8 \%)$ \\
\hline $\begin{array}{l}\text { I can use internet/computer to search to search } \\
\text { for useful information }\end{array}$ & $10(17.0 \%)$ & $8(15.4 \%)$ & $49(83.1 \%)$ & $44(84.6 \%)$ \\
\hline
\end{tabular}

Table 7 above indicates that both boys and girls have less than average perceptions about their ability to set their own learning goals (boys: $\mathrm{n}=28,47.5 \%)$, girls: $(\mathrm{n}=22,42.3 \%)$ ), lead others to accomplish a goal (boys: $\mathrm{n}=27$, $45.8 \%$ ), girls: $n=16,30.8 \%$ )), work with others to accomplish a goal (boys: $n=26,44.1 \%$ ), girls $n=28,53.8 \%$ )), manage time wisely (boys: $n=25,42.4 \%$ ), girls: $n=23,44.2 \%)$ ), and use internet to search for important information (boys: $\mathrm{n}=10,17.1 \%$ ), girls: $\mathrm{n}=8,15.4 \%$ )).

\section{Discussion}

This study was carried out to examine the prevailing gender gap in STEM (Science, Technology, Engineering, and Mathematics) attitudes and soft skills, and knowledge of role models among Nakivale secondary school students in Nakivale refugee settlement, rural southwestern Uganda. Results reveal that there is a gap between boys and girls towards their perceptions about STEM subjects. Compared to girls, boys were more likely to have positive attitudes about STEM; more boys than girls believed that they can get good grades in mathematics, and that they would consider a career in mathematics. More girls than boys believed that mathematics is hard. Compared to girls, boys are more likely to believe that they can do well in sciences, to consider science to be important in their future, and to agree that they can get good jobs with science. More boys than girls agreed that they like to imagine creating new products, are interested in what makes machines work, are considering a career in engineering/technology, and perceived themselves to be good at building and fixing things. Both boys and girls had less future interest in specific science subjects (e.g. physics, biology, chemistry), mathematics, technology and engineering. Both boys and girls had a lowest attitude in pursuing chemistry in future. Both boys and girls had fair knowledge about professionals who work as scientists, engineers, mathematicians, and technologists. Both boys and girls had low attitudes towards the $21^{\text {st }}$ century skills such as ability to set own learning goals, lead others accomplish a goal, work with others to accomplish a goal, manage time wisely, and 
use internet/computers to search for useful information. Students had the least attitude towards using the internet/computer skills.

The results indicate that girls had negative attitudes towards STEM, compared to their male counterparts. Girls' negative attitudes towards STEM have long been reported in literature (Desy et al, 2011; Unfried et al, 2014). Negative perceptions have an influence on performance as it was observed from the schools' records that boys were generally performing better than girls in STEM-related subjects. Literature also relates negative attitudes towards mathematics with poor academic performance in the subject (Akcay et al, 2010; Mahanta \& Islam, 2012). Interventions for altering the students' negative attitude and bias towards STEM-related subjects have the potential to improve academic performance while at the same time reducing STEM-related anxiety, emotional impediments and stereotypes (Maloney et al, 2013). In recognition of the important role played by women in Africa's growth and development in STEM, the African Union embraced a gender-sensitive Science, Technology and Innovation Strategy for Africa - 2024 (Union, 2014). In recognition of the important role that gender equality plays in attainment of the targets for the Agenda 2030, the UN General Assembly declared 11th February as the International Day of Women and Girls in Science (UNESCO, 2018). Despite these efforts, gender imbalances in STEM still exist. Unless addressed, the identified negative attitudes will continue to negatively influence girls' performance in STEM-related subjects, which will eventually limit their involvement in STEM careers, as their perceptions will shape their educational and professional choices. Limited involvement of girls/women in STEM careers will limit scientific creativity, excellence, and benefit to society. Additionally, gender imbalance in STEM hinders women's aspirations and advancement in science and technology, and constrains the achievement of gender equality, which is one of the 17 Sustainable Development Goals (SDGs). It also results in loss of capacity that has economic impacts well beyond the life of each individual girl/woman.

Reversing girls' negative attitudes towards STEM requires collective efforts; for example; parents need to provide supportive environments that offer time and other resources that can enable girls carry out their STEM-related home work, and develop creative thinking. Basics approaches such as shared responsibilities that involve boys in house chores, purchasing STEM-related toys to the girl child too, rather than toys that can instill in girls a perception that their role is simply that of child bearing, caregiving, and home making. At a school level, teachers, and other relevant stakeholders (such as instructors from higher institutions of learning) could organize mentoring sessions to encourage and interest girls in STEM as well as build confidence in their ability to excel in STEM-related subjects (Genoways, 2014). There is a need to build the capacity of teachers in using gender-responsive teaching approaches that give equal attention to students irrespective of their gender, which could potentially result in full and equal access to, and participation of girls in STEM. Utilizing modern digital technologies like electronic learning strategies can make STEM subjects more interesting, interactive, accessible, and easily related to real life applications, which can potentially enable girls learn the otherwise perceived hard STEM-related subjects in a simple and fun way (Musiimenta et al, 2019).

Both boys and girls demonstrated low attitudes towards the $21^{\text {st }}$ century skills (often called soft skills) such as goal setting, leadership skills, team work skills, time management and computer/internet skills. Literature calls for the need to supplement STEM/technical skills with soft skills (though often neglected), which are now acknowledged to contribute to workplace/business success than technical skills which are often overemphasized (Rosenberg et al, 2012; Strauss, 2017; Davidson, 2017; Willmot \& Colman, 2016). Young people experience substantial changes in schools based in refugee settlement given the ethnic diversity of teachers, fellow students and other members of the school community that they have to interact with. For instance, our study participants diverse ethnic backgrounds include Uganda, Rwanda, Burundi, Congo, Ethiopia, Sudan, and Tanzania. Given this diversity, being able to communicate effectively will enable them understand STEM concepts taught, contribute to classroom discussions, and ask questions in class, and adapt to the refugee environment. Soft skills in form of internet/computer skills could help students access modern learning resources and other important information from the internet (Musiimenta et al, 2019), stay in touch with their relatives living in their home country, and boost their employability. Soft skills have also been associated with positive youth development effects such as conflict and violence prevention, active and responsible citizenship, and improved health, including reproductive health (YEFG, 2017; Musiimenta, 2012). Integrating gender-sensitive skills training interventions into schools would address the current gaps in soft skills among young girls and boys in this setting.

Although boys had higher attitudes towards STEM than girls, both of them generally had low intentions of pursuing STEM-related subjects in future. Being a school within a refugee camp, students and teachers lack access to modern learning and teaching resources such as text books, internet, and computer skills (Musiimenta et al, 2019) which are crucial in studying STEM, given its practical nature. The demonstration of limited 
knowledge about STEM role models is not surprising since the context of a refugee settlement (where the school is found) is often characterized with children who are victims of poverty, and human rights abuses. Lack of role models denies students (especially girls) an opportunity to envision themselves in STEM careers, which would motivate them to pursue STEM. Access to STEM role models is reported to positively influence girls' perception about STEM (Kekelis \& Joyce, 2014). School girls within Nakivale refugee settlement generally lack female role models (e.g. females with exciting STEM jobs) that they would look up, learn from, emulate their success stories, and have a change of mindset early enough before they can make important choices for their career paths. Girls' exposure to women that have succeeded in STEM could help them relate to such women and aspire to be like them. Many girls in Nakivale refugee settlement continue to drop out of school mainly due to teenage pregnancies, and early/forced marriages, perhaps because they grow up seeing fellow females taking the same path.

The strength of the study is that it identifies gender gaps in attitudes towards STEM, and highlight constraints in accessing role models, and as well as acquisition of soft skills among students from a marginalized school found in Nakivale refugee settlement in rural southwestern Uganda. These insights can inform the development of innovative interventions to address the identified gaps. In addition, having been conducted in a rural refugee settlement in sub-Saharan Africa, the findings have implications for similar settings.

The study was limited by the fact that it was a descriptive cross sectional assessment carried out in a single class of a refugee-based school; the findings may not represent the views of the whole school and those of non-refugee-based schools. Larger experimental studies that involve many schools and go beyond descriptive analysis should be targets for future research.

In the nutshell, the results indicate that girls had negative attitudes towards STEM, compared to their male counterparts. Both boys and girls demonstrated low attitudes towards the $21^{\text {st }}$ century skills (such as goal setting, leadership skills, team work skills, time management and computer/internet skills). Both boys and girls had low intentions of pursuing STEM-related subjects in future, as well as limited exposure to STEM role models. Interventions to address girls' negative attitudes towards STEM, improve students' $21^{\text {st }}$ century skills, develop students' interest in STEM subjects/careers are urgently needed especially in marginalized areas such as refugee settlements. Implementing interventions to encourage refugee students' involvement in STEM subjects and improve their soft skills could contribute to reducing the current performance gap between rural and urban schools in Uganda, while at the same enabling students in refugee schools to compete favorably for jobs. Specific efforts to develop girls' interest in STEM subjects should focus on addressing the negative stereotypes and providing access to female role models.

\section{Acknowledgement}

The authors would like to acknowledge SPIDER (Swedish Programme for ICT in Developing and Emerging Regions) for funding (Dnr: SU - 323 - 5.1.2- 0419 -17) our on-going electronic learning project that provided a basis for this study. In addition, from 2012 to date, the authors have been receiving funding support from various sources (such as Google, Education Partnership Africa, and Association of Commonwealth Universities) aimed at encouraging the participation of girls and women in STEM-related fields. We appreciate Windle International, UNHCR, and the office of the Ugandan Prime Minister for providing access to Nakivale Secondary School. We are grateful to the head teacher, teachers, and students of Nakivale Secondary School for consenting to participate in this study.

\section{References}

Akcay, H., Yager, R. E., Iskander, S. M., \& Turgut, H. (2010). Change in student beliefs about attitudes toward science in grades 6-9. Paper presented at the Asia-Pacific Forum on Science Learning and Teaching.

Davidson, C. N. (2017). The new education: How to revolutionize the university to prepare students for a world in flux: Hachette UK.

Desy, E. A., Peterson, S. A., \& Brockman, V. (2011). Gender Differences in Science-Related Attitudes and Interests among Middle School and High School Students. Science Educator, 20(2), 23-30.

Dickerson, A., McIntosh, S., \& Valente, C. (2015). Do the maths: An analysis of the gender gap in mathematics in Africa. Economics of Education Review, 46, 1-22.

Faber, M., Unfried, A., Wiebe, E. N., Corn, J., Townsend, L., \& Collins, T. L. (2013). Student attitudes toward STEM: The development of upper elementary school and middle/high school student surveys. Paper presented at the the Proceedings of the 120th American Society of Engineering Education Conference. 
Genlott, A. A., \& Grönlund, Å. (2016). Closing the gaps-Improving literacy and mathematics by ict-enhanced collaboration. Computers \& Education, 99, 68-80.

Genoways, S. (2014). The Role of High Schools in Preparing Young Women for a STEM Career. Retrieved 20th August 2019, from https://www.unomaha.edu/college-of-education/moec/_files/docs/edad-9550-final-research-brief-genoways -spring2014-corrected-1-26-14.pdf

Kekelis, L., \& Joyce, J. (2014). How role models can make a difference for girls. Society of Women Engineers Magazine, 32-36.

Mahanta, S., \& Islam, M. (2012). Attitude of secondary students towards mathematics and its relationship to achievement in mathematics. International Journal of Computer Technology and Applications, 3(2), 713-715.

Maloney, E. A., Schaeffer, M. W., \& Beilock, S. L. (2013). Mathematics anxiety and stereotype threat: Shared mechanisms, negative consequences and promising interventions. Research in Mathematics Education, 15(2), 115-128.

Marginson, S., Tytler, R., Freeman, B., \& Roberts, K. (2013). STEM: country comparisons: international comparisons of science, technology, engineering and mathematics (STEM) education. Final report.

Musiimenta, A. (2012). A Controlled Before-After Evaluation a computer-based HIV/AIDS education on Students' Sexual Behaviours, Knowledge and Attitudes. Online Journal of Public Health Informatics, 4(1).

Musiimenta, A., Tumuhimbise, W., Nankunda, M., Bangumya, E., Atuhaire, J., Mugonza, R., .. . Mugaba, A. T. (2019). Electronic Learning May Improve the Teaching and Learning of Mathematics and Science in Marginalized Schools in Nakivale Refugee Settlement, Uganda: A Baseline Analysis. Journal of Education and Development, 3(2), 63.

Nuwagaba, A. (2012). Toward addressing skills development and employment crisis in Uganda: the role of public private partnerships. Eastern Africa Social Science Research Review, 28(1), 91-116.

Ochwa-Echel, J. R. (2011). Exploring the gender gap in computer science education in Uganda. International Journal of Gender, Science, and Technology, 274.

Rosenberg, S., Heimler, R., \& Morote, E.-S. (2012). Basic employability skills: a triangular design approach. Education+ Training, 54(1), 7-20.

Strauss, V. (2017). The surprising thing Google learned about its employees-and what it means for today's students. Washington Post, 20.

UNESCO. (2010). UNESCO science report 2010: The current status of science around the world. United Nations Educational, Scientific and Cultural Organization.

UNESCO. (2018). Celebrating the International Day for Women and Girls in Science. UNESCO Headquarters Paris, 7 Place de Fontenoy - Room IV.

Unfried, A., Faber, M., \& Wiebe, E. (2014). Gender and student attitudes toward science, technology, engineering, and mathematics. The Friday Institute for Educational Innovation at North Carolina State University, 51.

Union, A. (2014). Science, technology and innovation strategy for Africa 2024 (STISA-2024). Science \& Technology African Union Commission, Ed.

Watt, H. M. (2010). Gender and occupational choice Handbook of gender research in psychology (pp. 379-400). Springer.

Willmot, P., \& Colman, B. (2016). Interpersonal skills in engineering education.

YEFG. (2017). What Works in Soft Skills Development for Youth Employment? A DONORS' PERSPECTIVE. Youth Employment Funders Group.

\section{Copyrights}

Copyright for this article is retained by the author(s), with first publication rights granted to the journal.

This is an open-access article distributed under the terms and conditions of the Creative Commons Attribution license (http://creativecommons.org/licenses/by/4.0/). 